\title{
THE DEVELOPMENT OF A METHOD
} FOR CORE SAMPLING

\section{ALPHA-PLUTONIUM BUTTONS \\ D.M. Miller}

for

Atlantic Richfield Hanford Co.

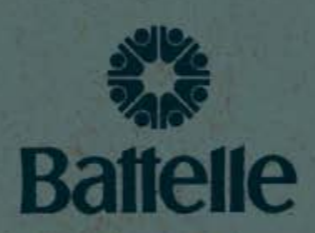

Pacific Northwest Laboratories

Richland, Washington 99352

\section{JULY 1973}

Prepared for the U.S. Atomic Energy Commission under Contract AT(45-1):1830 


\title{
NOTICE
}

The report was prepared as an account of work sponsored by the United States Government. Neither the United States nor the United States Atomic Energy Commission, nor any of their employees, nor any of their contractors, subcontractors, or their employees, makes any warranty, express or implied, or assumes any legal liability or responsibility for the accuracy, completeness or usefulness of any information, apparatus, product or process disclosed, or represents that its use would not infringe privately owned rights.

\author{
PACIFIC NORTHWEST LABORATORY \\ operated by \\ BATTELLE \\ for the \\ U.S. ATOMIC ENERGY COMMISSION \\ Under Contract AT(45-1)-1830
}

\author{
Printed in the United States of America \\ - Avallable from \\ National Technical Information Service \\ U.S. Department of Commerce \\ 5285 Port Royal Road \\ Springfield, Virginia 22151 \\ Price: Printed Copy 54.00; Microfiche \$0.95
}




\section{8}

THE DEVELOPMEITT OF $\wedge$ METHOD

FOR

CORE SNIPLIHIG ALPHA-PLUTOIIIUM BUTTDIS
Special Distribution

FIIIAL REPORT

JuTy 1973

to

\author{
Ntlantic Richfield Ilanford Company \\ P. 0. Box 250 \\ Federal Building \\ Richland, Washing̣ton 99352
}

by

D. 1. Mi1Ter

BATTELLE

PACIFIC IIORTIIIEST LABORATORIES

RICHLAND, WASHINGTON 99352 
THE DEVELOPHEITT OF A METIION

FOR

CORE SAMPLIIIG ALPIIA-PLUTOHIUIY BUTTOHS

by

D. M. Miller

SUMPIARY

At the request of the Atlantic Richfield lianford Company, the Fabrication Engineering Section of the Metallurny Developinent Department of Battelle, Pacific Northwest Laboratories conducted studies to determine the feasibility of extracting core samples from alpha-plutonium buttons. A core sample tool was fabricated and tested by the actual cutting of several core samples from the plutonium buttons. Analytical studies demonstrated the superiority of the core drilling syster as conpared to their twist drill method. Equiprient and operating requirements were identified, design concents were explored and evaluated, and specifications were written. $A$ core sampling machine and tooling vere purchased.

This equipment was tested and corrections and alterations were nade to provide a core drilling system suitable for production sampling of alpha-plutonium buttons. 


\section{LIST OF FIGURES}

Page

1 Initial Core Drill Fabricated of Heat-Treated

High-Speed Steel Shank with Tips of Carboloy Grade 895 Tungsten Carbide, Silver Soldered

in Place and Ground to Final Shape. . . . . . . . . . . . 3

2 Location and Identification of the Core and

Twist Drill Samples................ 6

3 Alpha-Plutonium Button with the As-Cut Core

Samples Still in Place.......... . . . . . . 8

4 Alpha-Plutonium Button with One Core Sample

Removed and Held in the Tool. . . . . . . . . . . . 8

5 Core Sample Tool . . . . . . . . . . . . . . . 15

6 Stop Bar Vesigned to Provide Convenient Sample

Location Adjustment . . . . . . . . . . . . . . . 22

7 Tube Change Made to Overcome Feed Problems . . . . . . . 23

8 Chip Catching Mechanism . . . . . . . . . . . . 25

9 Core Removal Tool . . . . . . . . . . . . . . . 27

10 Core Sampling Machine and Controls . . . . . . . . . 28

11 Close-Up of Core Sampling Apparatus . . . . . . . . . . 28

12 Core Sampling Machine . . . . . . . . . . . . . 29

13 Circuit Diagram of the Electrical Control System . . . . 33

\section{LIST OF TABLES}

1 Examnle of Sample Coding . . . . . . . . . . . . 5

2 Carbon Analysis Test Results ............. 9 
CONTEITS

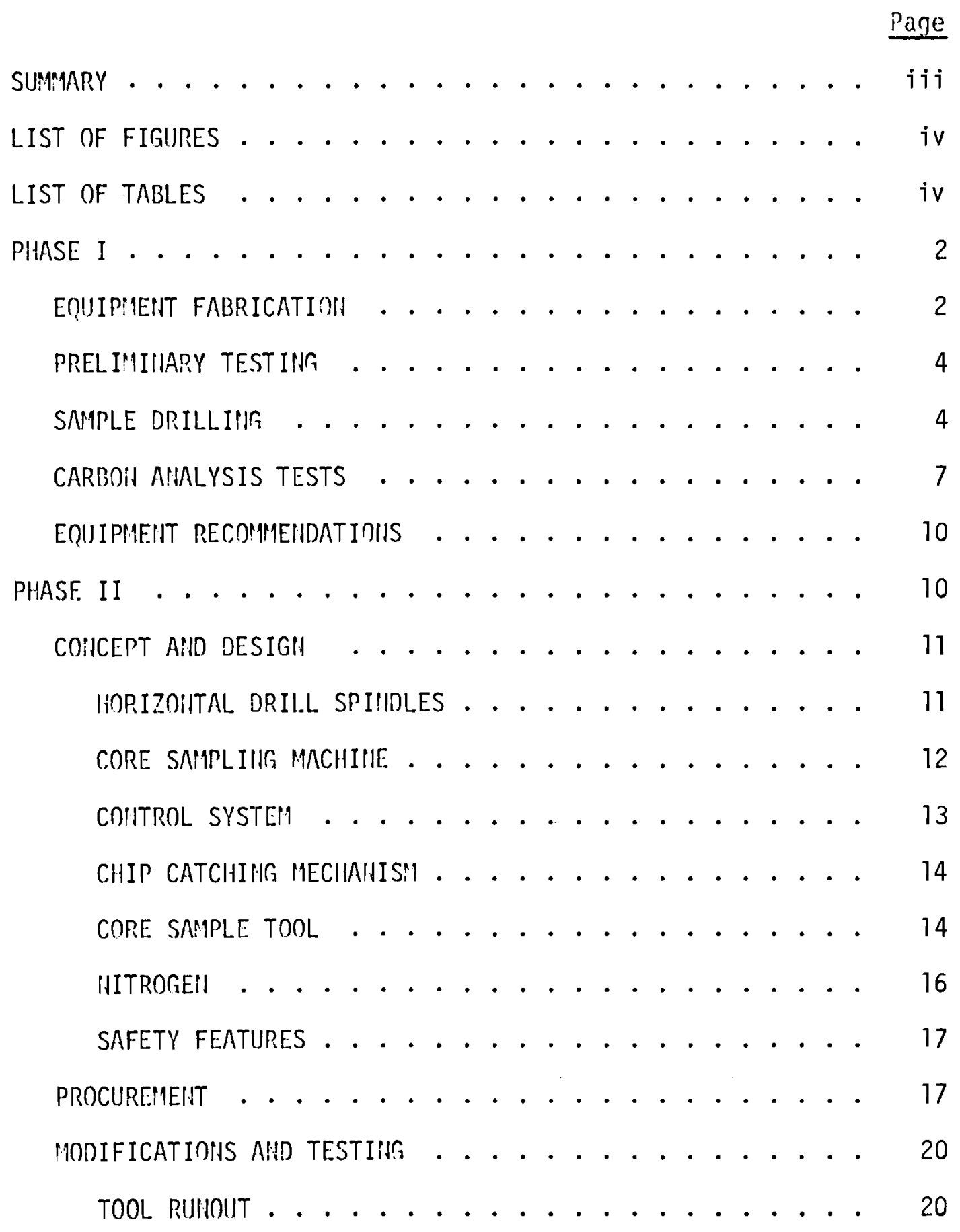




\section{CONTEIITS (contd)}

$\underline{\text { Page }}$

STOP BAR ADJUSTMENTT . . . . . . . . . . . . . . 20

FEEDING PROBLEIS .................. 20

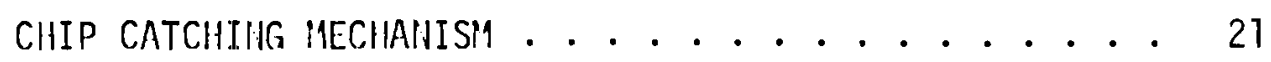

CORE REMOVAL TOOL . . . . . . . . . . . . . 24

DESCRIPTION OF THE CORE DRILLIIIG SYSTE!1. . . . . . . . . 24

COPE SAMPLIHG MACHIME . . . . . . . . . . . 26

CHIP CATChIIIG MECHAHISM . . . . . . . . . . 30

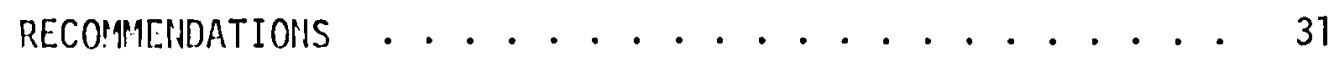




\section{THE DEVELOPMENT OF A METHOD}

FOR

CORE SAMPLING ALPHA-PLUTONIUM BUTTONS

by

D. M. Miller

FINAL REPORT

\section{INTRODUCTION}

At the request of $R$. D. Fox of Atlantic Richfield Hanford Company (ARHCO), a study was begun by Pacific Northwest Laboratories in October, 1971 to determine the feasibility of core sampling alpha-plutonium buttons. Phase I of this study included the design and fabrication of a suitable coring tool, a coolant delivery system, a sample extractor, and a limited number of tests to evaluate the technique, to identify the major equipment needs and to outline a production process.

As a result of this study a core sampling system was developed which produced more consistent sampling without the cross-contamination from the sampling tool. This method supplied a clean, uncontaminated metal core, 60 mils in diameter, with a minimum of vertical cross-contamination.

Because of its proven superiority in comparative analytical testing, the system was accepted and approved by ARHCO as a method superior to their present twist drill operation. As a result they sponsored the design and development of a core sampling production unit. During 
Phase II, drawings and specifications were developed and vendor-fabricated equipment was purchased which was subsequently tested and modified to make it ready for use in the production sampling of alpha-plutonium buttons.

The tasks described in this report are:

- The initial fabrication and testing of a core sampling toor,

- The conceptual and design work for the core drilling equipment and tooling,

- The writing of specifications and purchasing requirements, and procurement of the core sampling machine and core sampling tools,

- The testing of received equipment and the correcting of its deficiencies,

- The description of the equipment and its functions, and the making of recommendations to further improve its operation and efficiency.

\section{PHASE I}

\section{EQUIPMENT FABRICATION}

To determine the feasibility of extracting core samples from alphaplutonium buttons without the cross-contamination of carbon from drill wear, a core sampling tool (Figure 1) was fabricated combining a heattreated high-speed steel shank with tips of Carboloy grade 895 tungsten carbide which were silver soldered in place. The drill was then ground to final shape with the cutting edges notched to produce smaller chips and make them easier to expel. An inducer was fabricated to feed nitrogen 
BiNWL -1769

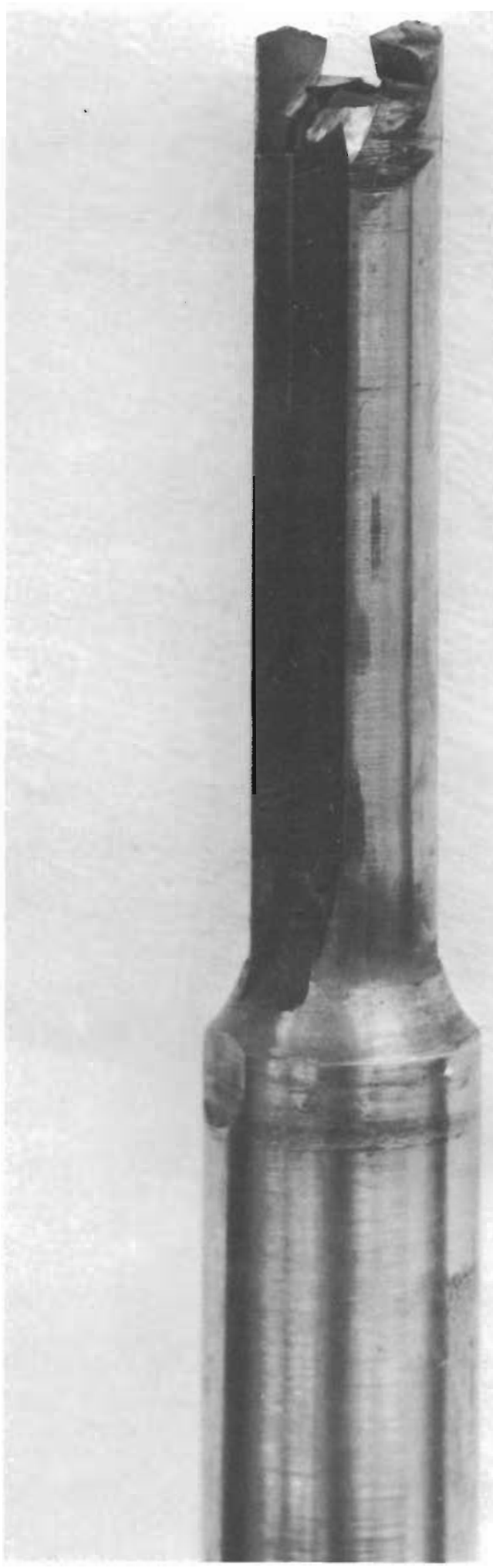

FIGURE 1. Initial Core Dril1 Fabricated of Heat-Treated High-Speed Steel Shank with Tips of Carboloy Grade 895 Tungsten Carbide, Silver Soldered in Place and Ground to Final Shape 
gas through the core sampling tool to provide cooling and to purge the chips from the hole as cutting progressed.

An additional effect of the nitrogen gas was to act as a quenching agent, causing the chips to become brittle and to break off because of rapid cooling and subsequent return to the alpha phase.

\section{PREL IMINARY TESTING}

The drilling operation was performed on a small jig borer within a plutonium glove box. Optimum machining parameters were $100 \mathrm{rpm}$ and $1 / 8 \mathrm{in.} / \mathrm{min}$ feed with $20 \mathrm{psig}$ nitrogen gas. The sample was cleanly cut and the chips were expelled from the cavity in the form of tight curls of $20 \times 30 \mathrm{mil}$ average dimension.

\section{SAMPLE DRILLING}

Five $31 / 2$ in.-diameter by 1 1/2-in.-thick production line alphaplutonium buttons weighing approximately $2 \mathrm{~kg}$ each were furnished by ARHCO for complete sampling. Five core drill samples and four twist drill samples were cut from each button. Of these five core drill samples one was a 3/8-in.-long emission spectrographic sample taken at a random location on the button. The four 60-mi1-diameter by 3/8-in.long analytical samples were cut from two 7/8-in.-deep holes, one at the center and one at the edge of each button. To avoid surface contamination, the first $1 / 8$ in. of material was discarded from each hole as part of the sampling technique before the core drill samples were cut; the remaining $6 / 8 \mathrm{in.}$ was broken into two $3 / 8-i n$. core drill samples.

After removing the surface contamination, four twist drill samples were cut to a depth of $3 / 4 \mathrm{in}$. at analogous locations to those of the 
core drill samples, one at the center and one at the edge; two samples (A and $B$ ) were taken from each hole. The location of each sample is shown in Figure 2.

Each sample was then coded with a random number to avoid prejudgement of the sample results, thereby yielding unbiased analyses. The analytical core drill samples were identified by numbers 1 A and $B$ and $2 A$ and $B$, the core drill emission spectrographic samples by letter $C$, and the twist drill samples by numbers $3 A$ and $B$ and $4 A$ and $B$. An example of the coding is given in Table I.

Table I. Example of Sample Coding

Sample Number Random Number

\section{Core Drill}

$\begin{array}{lll}1 \text { A } & 13 \\ 1 \text { B } & 28 \\ 2 \text { A } & 15 \\ 2 \text { B } & 22 \\ C & 17\end{array}$

\section{Twist Drill}

$3 A$

$3 \mathrm{~B}$

$4 \mathrm{~A}$

4 B

\section{9}

24

16

21

Because of the difficulty of breaking the core drill samples, a 3/16-in.-diameter by 3-in.-1ong piece of dril1 rod was drilled to closely fit the core; this made a satisfactory break-off tool. To prevent surface 


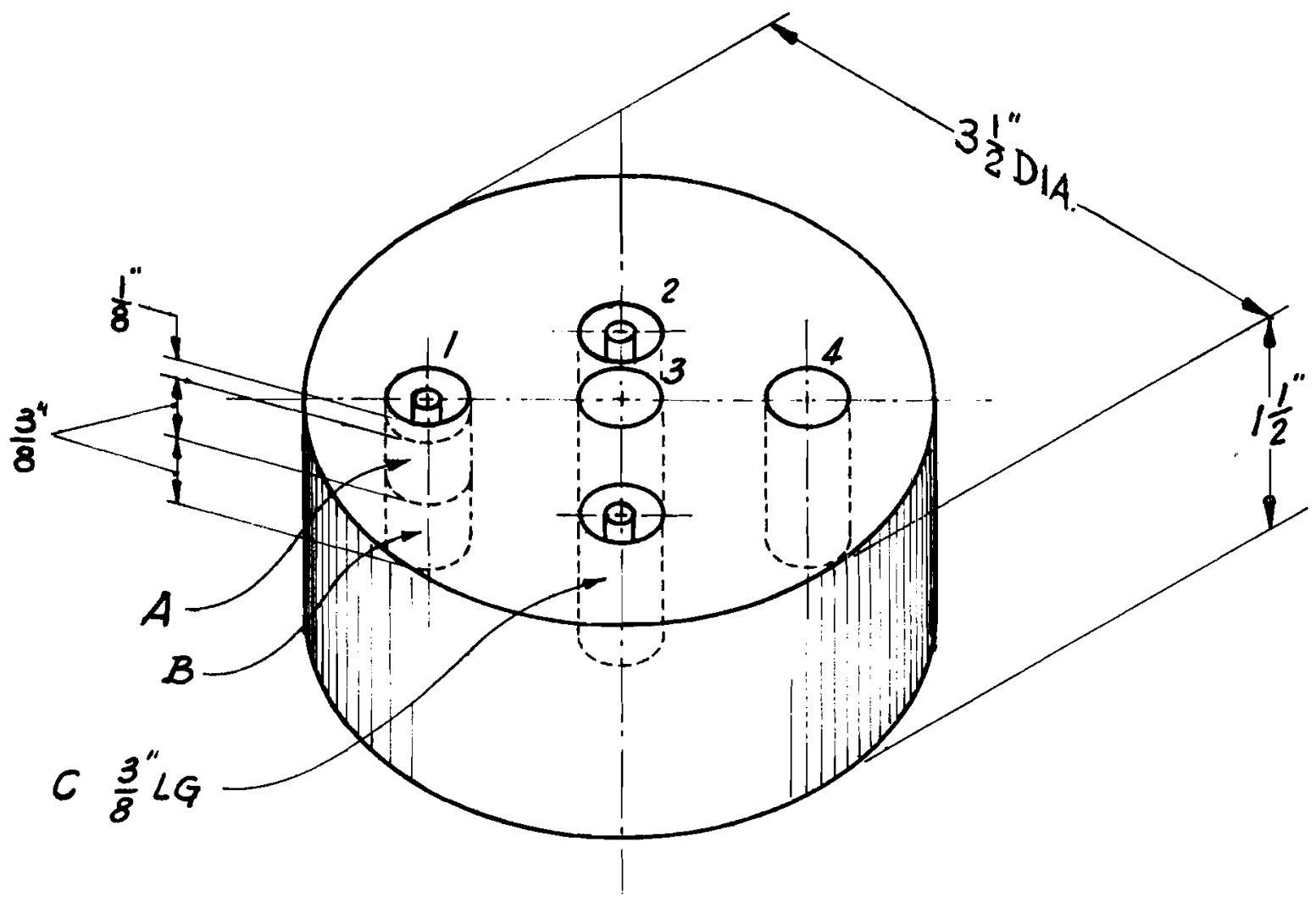

A - TOP SAMPLE

B - BOTTOM SAMPLE

1 - CORE DRILL EDGE SAMPLE

C - EMISSION SPECTROGRAPHIC SAMPLE

4 - TWIST DRILL EDGE SAMPLE

2 - CORE DRILL CENTER SAMPLE 3 - TWIST DRILL CENTER SAMPLE

FIGURE 2. Location and Identification of the Core and Twist Drill Sample 
contamination, the equipment and all exposed surfaces were washed with liquid freon and then covered with clean aluminum foil. The individual samples were then carefully handled, packaged and identified. To prevent oxidation a heavy purge of nitrogen gas was required.

Approximately $123 / 8$ inches of samples were cut with the single core sample tool. Its ability to cut a distance of this length demonstrates the quality of its design. A hairline wear land was observed on the core drill cutting edge but good clean samples were produced throughout the test. A small amount of galling took place on the margin and rake face of the carbide tips because of a lack of rigidity in the set-up and the resulting misalignment. Some galling also occurred between the drill shank and the rotary inducer which was not unexpected and can be easily prevented by using solid tungsten carbide drills.

Figures 3 and 4 are photographs displaying an alpha-plutonium button with two core samples showing; in Figure 3 the core samples have not been removed and in Figure 4 one core sample has been removed and is in the tool. These photographs were taken during the preliminary testing of the equipment and are not representative of the final location of the holes.

\section{CARBON ANALYSIS TESTS}

ARHCO conducted a series of carbon analysis tests on the completed core dri11 and twist dril1 samples. The average carbon content for the core dri11 samples was 142 ppm versus 298 ppm for the twist drill samples; this demonstrated the validity of the core sampling method. These results are shown in Table 2 . 


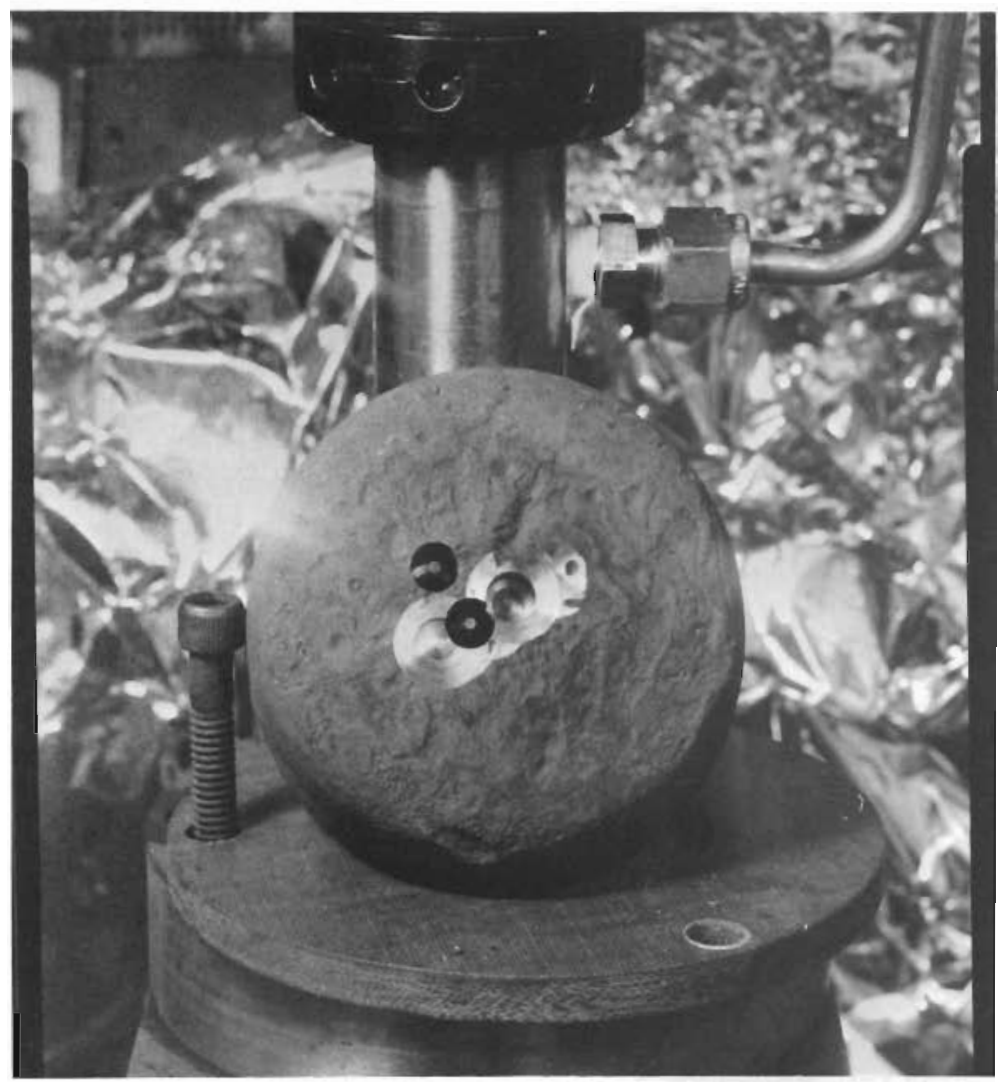

FIGURE 3. Alpha-Plutonium Button with the As-Cut Core Samples Still in Place

FIGURE 4. Alpha-Plutonium Button with one Core Sample Removed and Held in the Tool

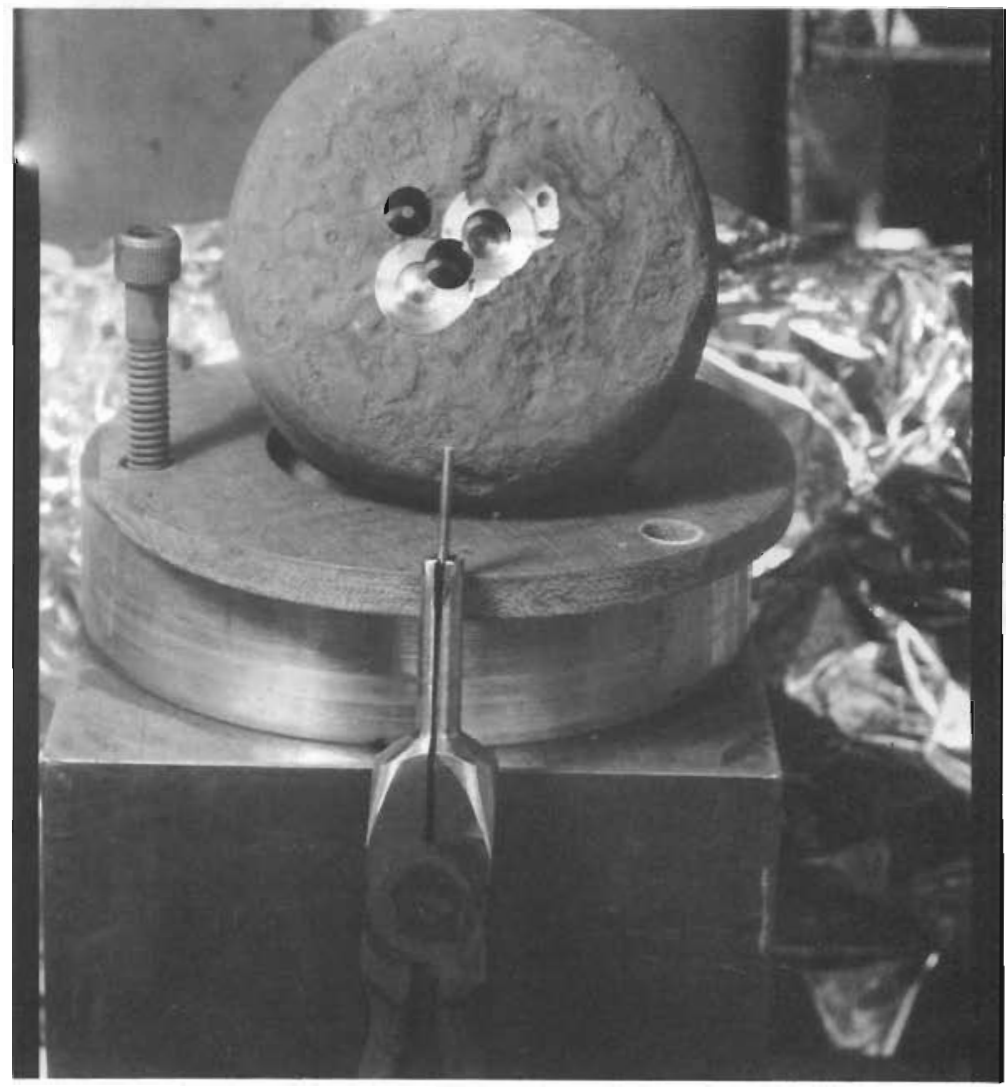


Table 2. Carbon Analysis Test Results (ppm)

\begin{tabular}{|c|c|c|c|c|c|}
\hline \multirow[b]{2}{*}{ Sample Number } & \multicolumn{5}{|c|}{ ARHCO Button Identification Numbers } \\
\hline & $\underline{364}$ & 366 & 446 & 447 & $\underline{459}$ \\
\hline \multicolumn{6}{|l|}{ Core Drill } \\
\hline $1 A$ & 130 & 102 & 118 & 85 & 152 \\
\hline $1 \mathrm{~B}$ & 245 & 159 & 164 & 33 & 127 \\
\hline $2 \mathrm{~A}$ & 151 & 140 & 106 & 42 & 148 \\
\hline $2 B$ & 137 & 311 & 109 & 33 & 236 \\
\hline \multicolumn{6}{|l|}{ Twist Urill } \\
\hline $3 A$ & 225 & 426 & 360 & 115 & 353 \\
\hline $3 B$ & 220 & 129 & 204 & 249 & 272 \\
\hline $4 \mathrm{~A}$ & 449 & 614 & 429 & 135 & 470 \\
\hline $4 B$ & 400 & 270 & 292 & 210 & 268 \\
\hline \multicolumn{6}{|l|}{ Average } \\
\hline Button Line ${ }^{(a)}$ & 400 & 375 & 160 & 375 & 190 \\
\hline Twist Drill & 322 & 332 & 321 & 177 & 341 \\
\hline Core Drill & 165 & 178 & 124 & 77 & 165 \\
\hline
\end{tabular}

(a) original carbon analysis 


\section{EQUIPIIENT RECOMMENDATIONS}

- The development and acquisition of the following equipment was recommended to improve the production process:

Solid tungsten carbide core sampling tool for its non-galling characteristics,

Optimum drill design consisting of proper back taper, minimal margin width, and adequate flute geometry, Rigid boring type spindles on the machining heads, Rigid work piece clamping device andmounting mechanism, and Design and fabrication of a suitable chip catching system.

It was also recommended that optimum spindle speed, feed rate, and gas coolant pressure be established for the production process.

As a result of Phase I, it was concluded that the core drilling system would make a good production sampling process because:

- It provided consistently lower results (ppm carbon) than the twist drill sampling method.

- A difference could be statistically calculated using data obtained from the core samples, whereas, variations in the twist drill carbon analyses were so large that statistically no difference could be detected among the analyses of the five buttons.

- It provided a more stable base for analytical development.

\section{PHASE II}

Phase II was begun with the objective of supplying ARHCO with a production core drilling system which would provide core samples for analysis. This included the design and fabrication of the equipment, 
equipment tests and modifications, and the definition of routine set-up and operating parameters. This unit was to provide samples of minimum size and at least two grams in weight. The samples had to be long enough to be representative of the thickness of the button and at the same time the hole had to be kept small to avoid waste in chips, therefore, it was decided to cut the samples $100 \mathrm{mils}$ in diameter by $3 / 4 \mathrm{in}$. to $7 / 8 \mathrm{in}$. in length. This would provide the 2 grams of weight, the representative sample in length and keep the drill diameter to a minimum $5 / 16$ in.. To avoid contamination of the sample, operator handling had to be kept to a minimum. Cross-contamination between samples had to be avoided and an inert cover gas used to prevent sample oxidation and to minimize the potential of fire during the sampling process and subsequent storage. CONCEPT AND UESIGN Horizontal Lri11 Spindles

One of the major design innovations that was evaluated and adopted was the horizontal drill spindle. This type of spindle simplified the loading and unloading of the buttons by making the chuck more accessible to the operator, allowed the chip catcher to be of a smaller and simpler design, and prevented the chips from falling back into the hole. Sample extraction was also enhanced because the extraction process was unaffected by gravity.

A spotfaced area was needed to give the chip catcher a sealing surface to contact and also to clean the outer surface of the buttons before sampling. Because of this a second drilling spindle was added to the core 
drilling system to allow both the spotfacing tool and the core sample tool to remain chucked; this minimized the radiation exposure to the operator and saved time by avoiding a complicated tool changing problem. Core Sampling Machine

To support the machine spindles and the work slide, a base was specified of 1/2-in.-thick steel plate, keyways were machined in the plate for alignment of the machining heads and adjustments were provided to allow the machining heads to be positioned at a minimum of 2 in. to a maximum of 6 in. from the collet chuck face to the maximum length of the work surface. The work slide was mounted on a bracket, fabricated of 3/4-in.-thick steel, facing the spindle centerline at 90 degrees and attached to the base plate. The purpose of the work slide was to position the button in front of each spindle for its respective operation and for location between spindles during chucking, unchucking, and sample extraction. A 6-in. 3-jaw universal lathe chuck with two-piece jaws was mounted on the work slide to hold the buttons rigidly at machine spindle centerline height. An air cylinder provided positioning capability for the work slide, it was controlled by a balanced-to-center four-way valve. A chiptight cover was added to protect the exposed surface of the work slide.

After an extensive search through vendor catalogs and many telephone calls inquiring about drilling equipment, it was concluded that there were no suitable commercial horizontal drill units available with coolant application through the spindle. The thought of modifying the available equipment was investigated and discarded because of the difficulties involved. It became apparent from this search that a nitrogen gas inducer 
would have to be designed into the chip catching mechanism. This addition necessitated making the core sample tool design longer by the distance required to pass through the inducer.

One of the most demanding restrictions for the core sampling machine was the small size of the glove box in which it was to be installed. It was an existing piece of equipment and its inside dimensions were 32 in. by $31 \mathrm{in.}$, therefore everything had to be designed to fit within these dimensions.

Control System

The control system for the core sampling machine is comprised of the nitrogen gas system and the electrical system.

The nitrogen gas system supplies pressure to the automatic machining heads. It is a substitute for the air normally used and provides force to operate the rapid-advance feed and rapid-witindrawal cycles of the two machining heads, as well as, the work slide actuating cyclinder. The controls for the nitrogen system are a pressure regulator and a gauge for each machining head and the four-way balanced-to-center valve which is used to control the work slide actuating cylinder.

The electrical system supplies driving power to the machining head motors and is the means used to control the core drilling system. The control station consists of a tachometer which indicates the spindle speed and a motor controller unit which incorporates a speed regulating knob, an on-off switch to control the AC supply, and the start-stop switch to operate the motor for each machining head. One cycle-start switch and one rapid-withdrawal switch are mounted in the control panel; these operate 
either machining head depending upon the location of the work slide as positioned by the previously described four-way control valve.

By means of these controls the machining of the core sample is conducted semi-automatically from outside of the glove box; the only time the operator is required to have his hands near the plutonium is during loading and unloading of the button in the chuck, while extracting the core sample, and when removing the chips from the container. Chip Catching Mechanism

To avoid excessive exposure of personnel to radiation, to maintain cleanliness within the glove box, and to provide a source of additional samples if the need arose, it was necessary to develop a chip catching mechanism. A design was conceived incorporating a nitrogen inducer with tungsten carbide bushings, which also acted to guide and support the core sample tool. A means of spring loading the mechanism was provided as was a retracting device. The chip catcher was also designed to act as a protective device completely covering the core sample tool when it is not being used.

Core Sample Tool

Our previously successful experience with Carboloy grade 895 tungsten carbide, as the cutting tool material best suited for plutonium, led to the decision to specify that grade for the core sample tool cutting tips. This was the same grade out of which the Phase I core sample tool cutting tips were made.

The core sample tool (Figure 5) was designed for a one inch-maximum cutting depth. This depth was chosen because tool frailty and any misaligrment could cause problems if greater drilling depths were attempted. 


\section{NOTCHED TO REDUCE CHIP SIZE}

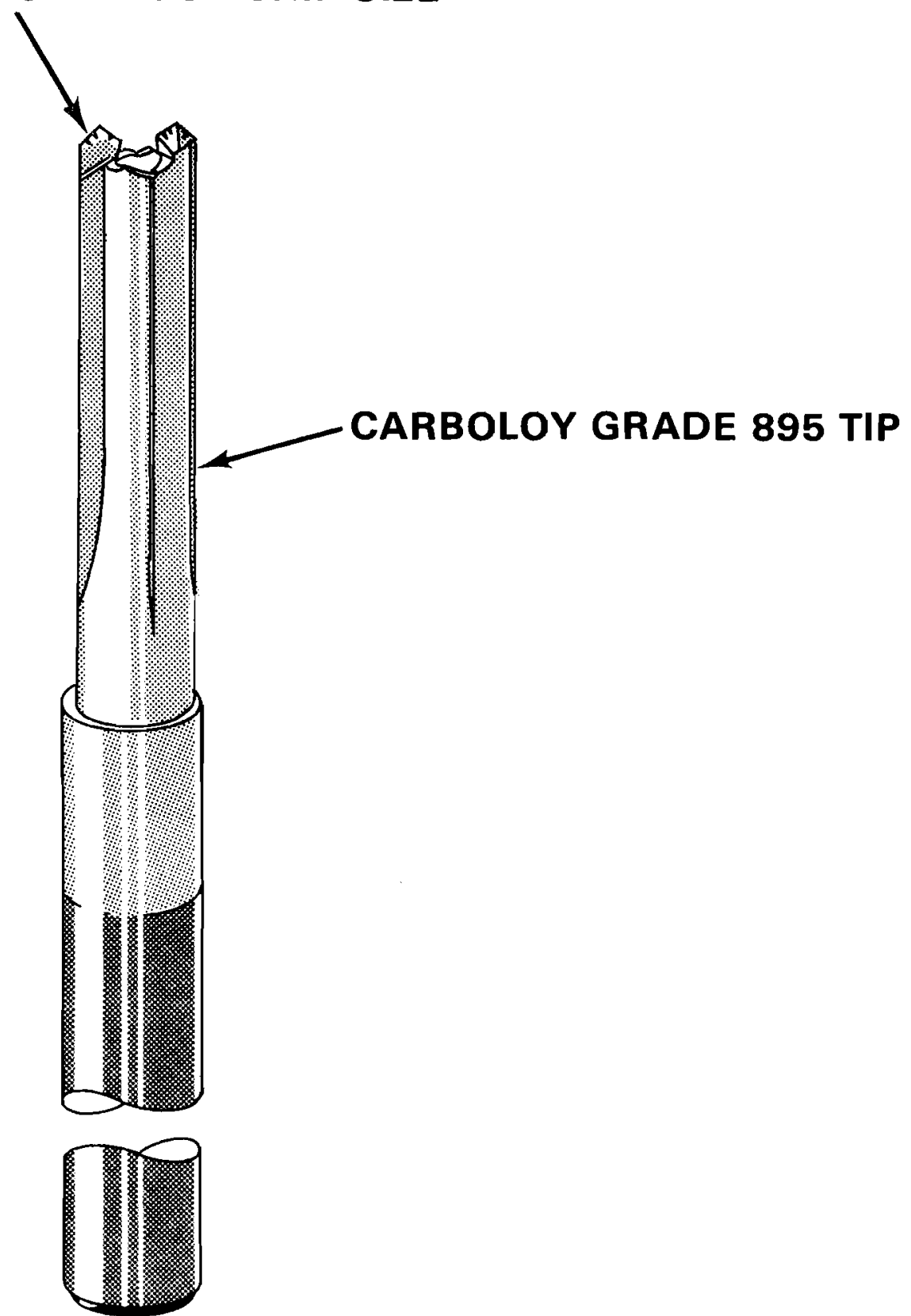

FIGURE 5. Core Sample Tool 
For the tool to reach this depth, pass through the chip catcher, and have enough length to be held by the collet chuck, it had to have an overall length of $51 / 2 \mathrm{in}$. The required inside dimensions of the core sample tool tip needed to form the 100-mil-diameter core necessitated an 00 of $5 / 16 \mathrm{in}$. for the strength of the cross section and to provide room in the flutes for the chips to escape. This tip portion of the tool was $11 / 2$ inches long. The shank section, which comprised the remaining $4 \mathrm{in.}$, was made $3 / 8 \mathrm{in}$. in diameter for added stiffness. A choice of manufacturing methods was specified--either a two-piece brazed construction with Carboloy grade 895 tip on tough grade carbide shank or a11 Carboloy grade 895 .

The end-cutting edge angles of the cutting tips conform to conventional gun drill design practices. They were notched to assure very narrow easy-to-expel chip sections. Extreme relief angles of $15^{\circ}$, used both on the inside and behind the cutting edges, and the narrow margin of $10 \mathrm{mil}$ were features of the core sample tool tip. They were necessary because of the tendency of alpha-plutonium to gall and to weld to itself and to the cutting tool under the absolutely dry conditions which were required to avoid contamination of the sample. When the tool relief angle is large and the edge margin is narrow, galling cannot occur because the area of contact, whereby the plutonium could cling to the tool is kept so smal1 that adherence cannot occur.

Nitrogen

A gas was needed to expel the chips from the hole during drilling and to actuate the work slide cylinder and the advance-feed and witindrawal 
cycles of the machining heads. Because nitrogen is inert and therefore, prevents oxidation, it is normally used with plutonium as a means of purging a glove box of oxygen. It is inexpensive and readily available. It could have no affects on the sample analysis because the nitrogen content would not be assayed. For these reasons, it was selected as the gas to be used within the core drilling system.

\section{Safety Features}

The following safety features are incorporated into the core drilling system:

- Micro-switches which form circuit interlocks were added to the stop bar which prevents spindle operation of the machining units during loading and unloading of the alpha-plutonium buttons.

- The end of the core drill is covered by the chip catcher when it is not cutting.

- A guard was fabricated to cover the spotfacing tool in its retracted position.

- The semi-automatic operation of the equipment makes manual manipulation unnecessary and eliminates radiation exposure to the extremities during the actual sample cutting.

PROCUREMENT

Once the conceptual work was completed, purchase specifications were written outlining the requirements for the core drilling system. A decision was made to have the core sampling machine fabricated as a unit by a competent vendor rather than buy the components at various places and assemble them. This would reduce costs and make one supplier responsible. 
To accomplish this vendor information drawings and specifications were made for the core sampling machine and the core sample tools. All the important requirements and restrictions for the core sampling machine were listed but no exacting details were called out. This gave the vendors as much latitude as possible yet required them to meet the overall needs. On the other hand, tolerances for the core sample tools were called out quite closely to be sure that what was obtained was exactly what was needed.

Initial bid requests, vendor search, and equipment purchase requests for bids were placed in May 1972. Because of the unconventional design and the small number of parts requested, only one unsatisfactory response was received. Another request was, therefore, made in September 1972; in answer to this request a successful bid was made by Perine Machinery and Supply Company, Inc., 5219 Fourth Ave. So., Seattle, Washington 98108. The Perine Company then subcontracted the fabrication of the core sampling machine to Wilkins and Associates, Inc., 601 Alexander, Tacoma, Washington 98421. Standard Sales Co., P. O. Box 191, Renton, Washington 98055 responded successfully on the core sample tool; they, in turn, subcontracted its fabrication to Clyde F. Richert, Inc., 34480 Goddard Rd., Romulus, Michigan 48174.

The core sampling machine was delivered onsite by the Perine Company in early February 1973. The basic machine was well made of good material and components and appeared satisfactory. Several items, however, were lacking from the control system; these shortages were later corrected.

Boring type spindles were called out with a minimum 2-in. operating stroke. Continuously variable spindle speeds from 100 to $800 \mathrm{rpm}$ assured 
that correct rotational speed was available. Although the $1 / 2 \mathrm{HP}$ electric motor could supply two or three times the torque needed at the tool, it was selected in lieu of a smaller motor which if fully loaded at slow rotational speeds would tend to overheat; the extra power eliminated the possibility of this problem and assured long lasting continuous duty operation.

A fully automatic air-actuated machining cycle was called for with adjustable rapid-travel distance, adjustable feed stroke length, a positive depth stop, and rapid withdrawal of the tool at the end of the drilling cycle. An infinitely variable feed rate adjustment was also requested to provide the very slow feed necessary because of the low tool rotational speed. Because of the length of the core drill, the specifications of $.0005-i n$. TIR tool runout at the collet nose and .002-in. TIR at 5 in. from the collet nose were required; therefore, pre-empting the use of universal type collet chucks.

The size of the existing glove box restricted the overall width and length dimensions of the machining unit to $32 \mathrm{in.}$ in length by $31 \mathrm{in}$. in width. Only one vendor responded to the bid requests because they were the only vendor with machining heads small enough to fit the confining space.

The mechanical components were required to be permanently lubricated and sealed to prevent oil or grease from contaminating the samples. Because of the in-line oilers on the air supply to the machining unit actuating system, the air exhaust ports also had to be provided with fittings for connecting remote exhaust 1 ines.

Eleven of the twelve core sample tools ordered were delivered by the Standard Sales Company early in February. A11 of them were rejected upon 
visual inspection because of their chipped and defective cutting edges. Nine of these were returned to the factory for rework of the cutting edges. Two were retained and used for experimental work on the core sampling machine; one was broken in initial testing and another was broken during final testing due to a feeding problem with the near machining head.

When the nine tools were returned from the factory, they were again unsatisfactory because of their chipped cutting edges. Al1 nine were reground in our shop to correct their chipped cutting edges and point concentricity; they are now in condition to perform satisfactory work.

\section{MODIFICATION AIND TESTING}

As a result of testing and trial runs, modifications were made to correct deficiencies in the machining units and the control system, as well as, in the core sample tools.

Tool Runout

Observation revealed that the core sample tools ran exceptionally true in the chuck but that they started to wobble when cutting commenced. Reinforcement of the drill guide diminished this wobbling, however, regrinding the cutting edges so they were exactly concentric with the tool shank completely corrected the runout. The core sample tool blue print was then revised by adding tolerances to assure correctly made point concentricity. Stop Bar Adjustment

The core sampling machine, as received, had the work slide stops mounted on the base plate with no limit switches attached. This was unsatisfactory for a glove box installation so a completely new adjustable 
stop bar (Figure 6) was fabricated incorporating one adjustable and one fixed stop, which worked against the cylinder rod to work slide mounting bracket, thus preventing any binding of the work slide. These stops were positioned to permit the regulation of the adjustable stop until the slide movement was confined to the exact center-to-center distance of the machining head spindles. The two micro-switches were mounted rigidly to the stop bar and adjusted to prevent the machine spindles from operating until the work slide was correctly positioned in front of it; this interlock allows the operator to safely load and unload the button, because neither machine spindle can start. A bracket was mounted on the cylinder support incorporating a single locking screw, which allows the stop bar to be adjusted so a sample can be taken from any desired position on the button. Feed Problems

For the near drilling unit to function properly, it had to rotate the tool slowly, approximately $100 \mathrm{rpm}$ and to feed the tool into the button at the approximate rate of 1/8 in. per minute. During the experimental operation of this unit, it was revealed that the feed rate gradually diminished. It fed slower on each successive cycle until on the third or fourth cycle, it stopped completely. When this occurred and the control was readjusted to start the feed, a rapid surge forward resulted causing the tool to break.

This hydraulic silting problem was resolved by installing a bypass loop of tubing to the front of the manifold as shown in Figure 7 . Air pressure was applied through the tubing which was in opposition to the hydraulic feed pressure and caused the feed valve to open wider to achieve the $1 / 8$ in. per minute feed rate. 
BNWL-1769

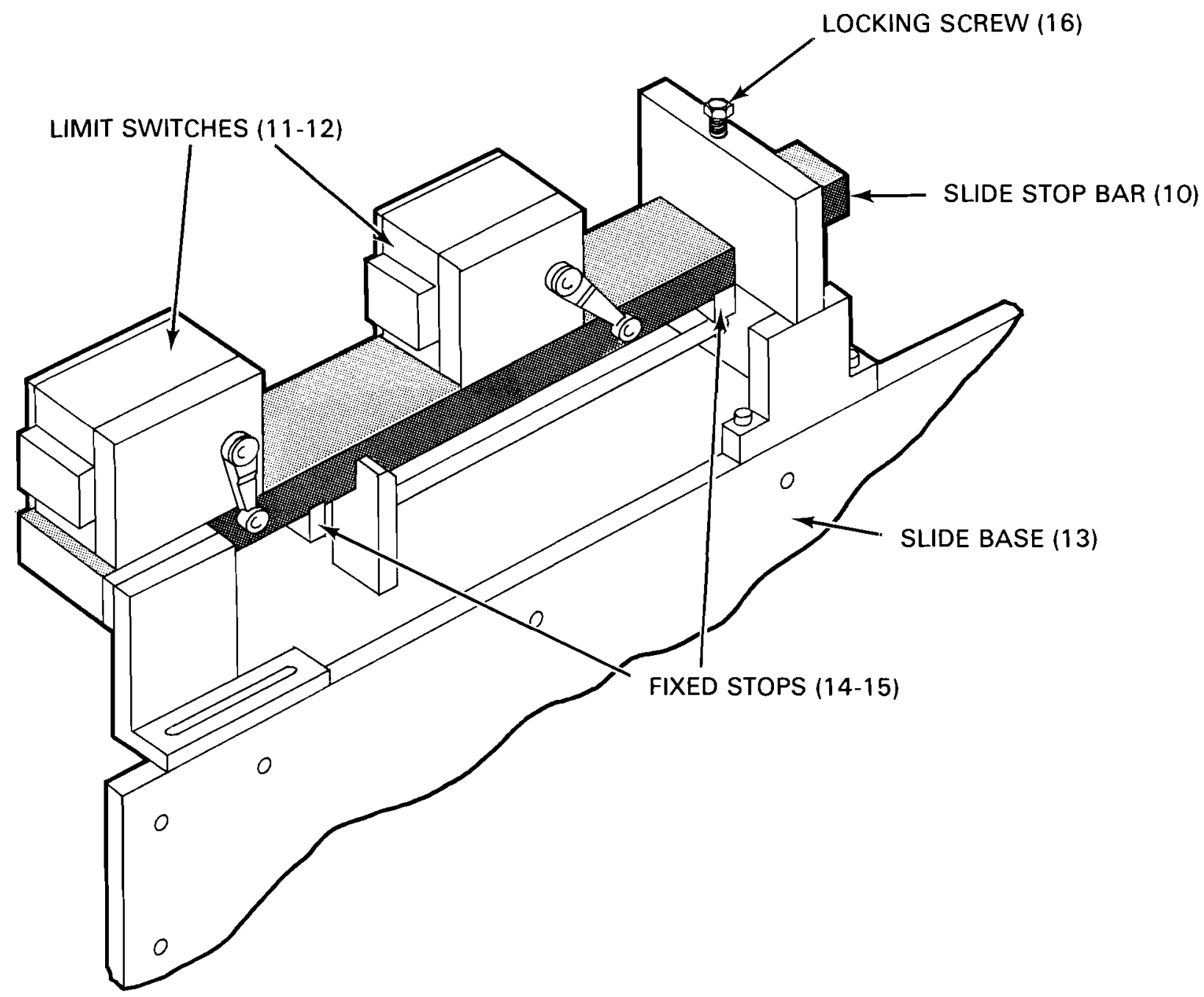

FIGURE 6. Stop Bar Designed to Provide Convenient Sample Location Adjus tment 
BNWL- 1769

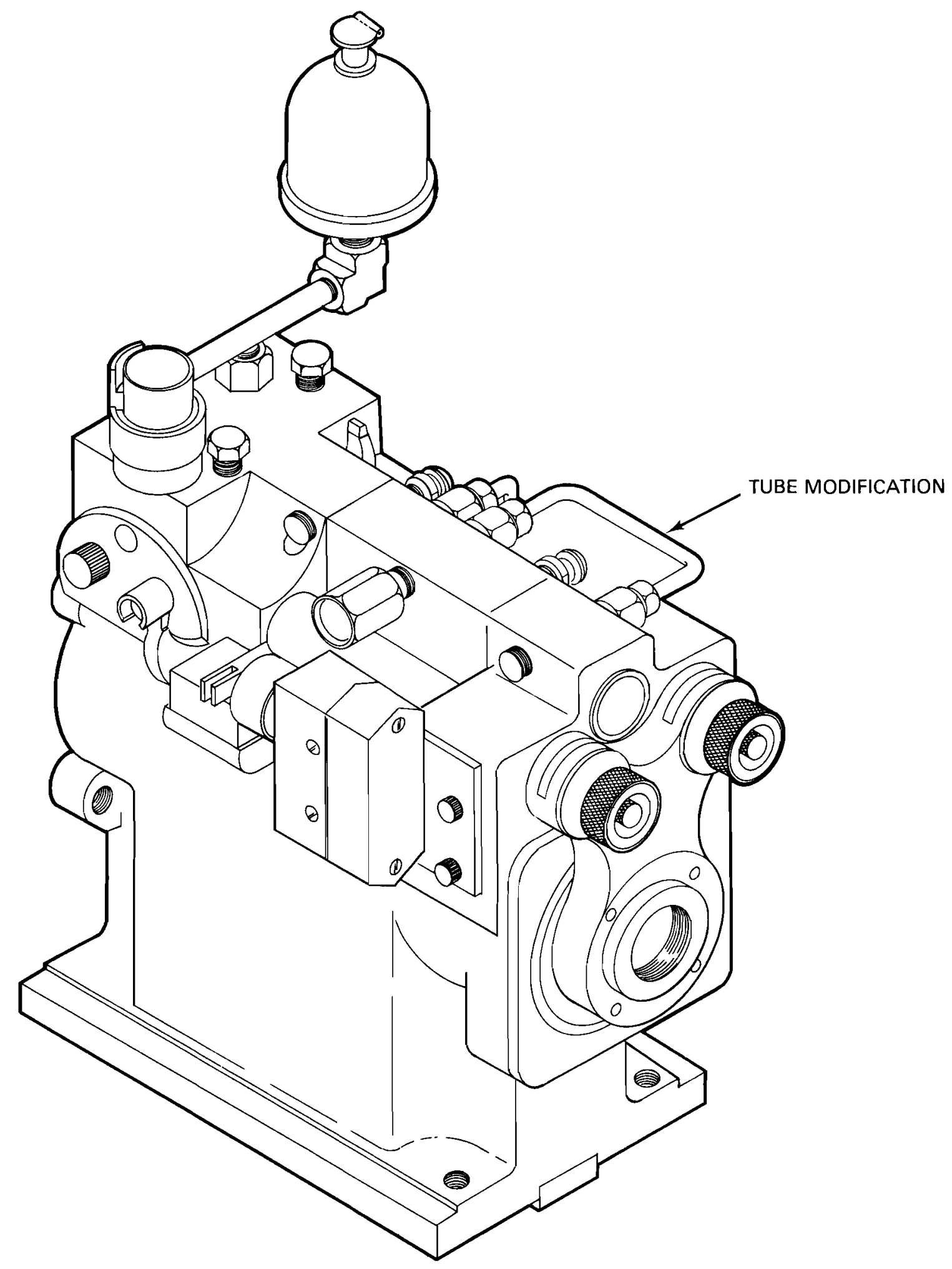

FIGURE 7. Tube Change Made to Overcome Feed Problems 
A stop pin and an adjustable clamp arm were applied to the valve regulating knob as a means of opening the feed valve and returning it to exactly the same setting. The regulating knob can now be adjusted to provide the correct feed rate and the adjustable clamp arm can be tightened with the arm firmly against the stop pin. This permits the feed regulating valve to be opened almost a full turn for flushing away the accumulated hydraulic silt and then to be returned to its exact previous setting.

\section{Chip Catching Mechanism}

The initial chip catching mechanism, as originally designed, was not substantial enough to support the core sample tool as it entered the button. This became apparent during the first test series; as a consequence, modifications were made to make it more substantial.

The chip catching mechanism (Figure 8) was stiffened and strengthened to support and guide the core sample tool. To accomplish this the support bracket (3) was increased in thickness and in dimension to give the best possible support to the two ball bushing shafts (20). These shafts provided support for the guide plate (4) by means of the two ball bushings(13). The size of the guide plate was increased to accommodate the bushings and transmit this additional support to the chip catcher (2). Core Removal Tool

It was necessary to design a new core removal tool because of the difficulty of removing the core sample from the brass test pieces, which were being used as stand-in material for plutonium in Phase II. This new tool also provided a more positive means of breaking off and removing the core samples from the alpha-plutonium buttons than the original break-off 


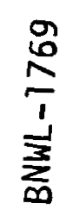

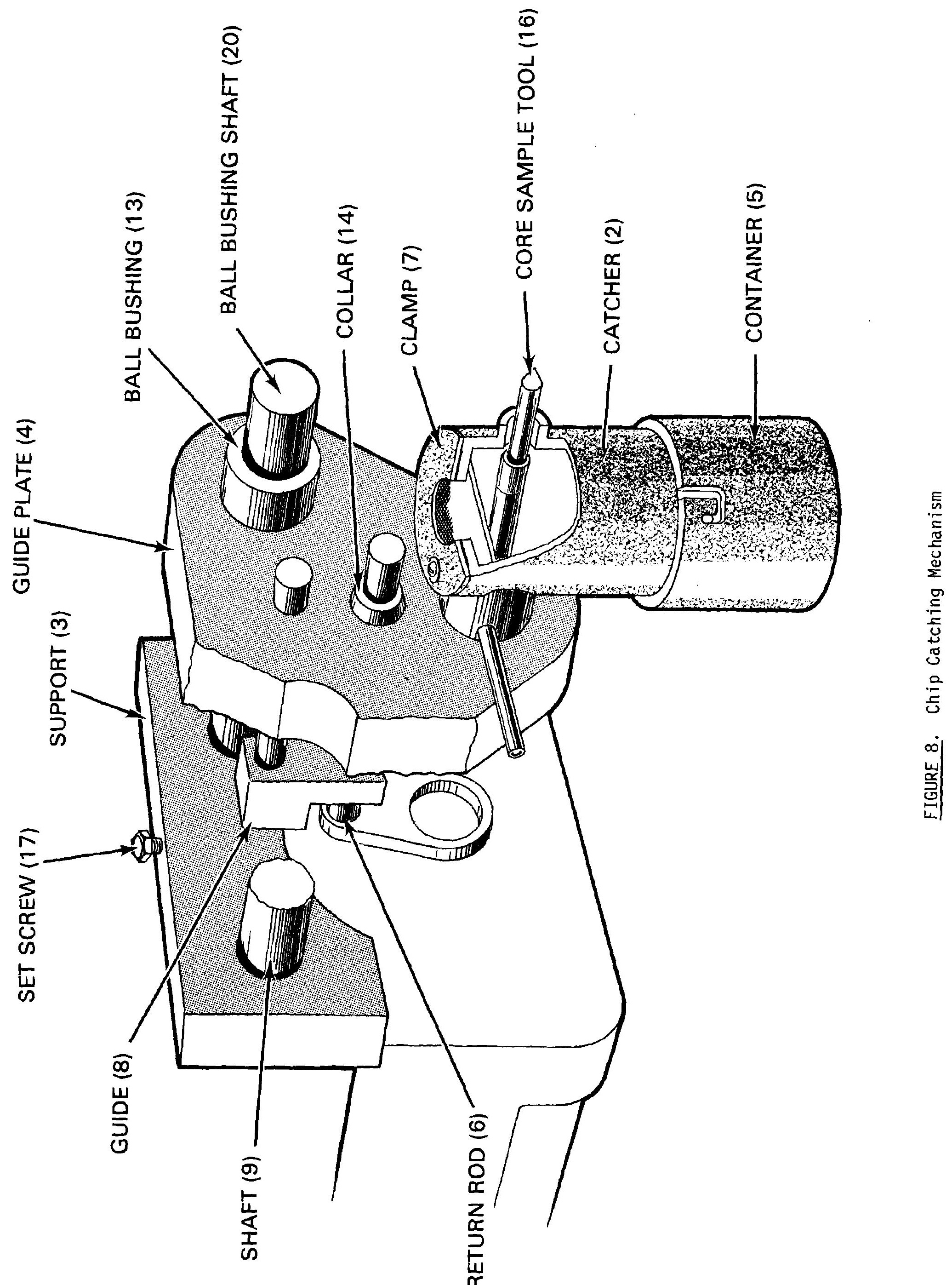


tool used in Phase I. As shown in Figure 9, the core removal tool (A) is inserted into the drilled hole around the core sample (B). Hand pressure is then applied to the core removal tool causing it to pivot over the fulcrum point $(C)$ as it bears against the wall of the hole. This applies shearing force at the base of the core at a leverage ratio of 18 to 1 and causes the sample to break off. The core sample is now contained in the hole in the tool and it is easily dumped into a sample vial without further handling.

DESCRIPTION OF CORE DRILLING SYSTEM

Core Sampling Machine

The core sampling machine, as shown in Figures 10, 11, and 12, consists of two Hause model $\mathrm{J}-2$ power feed machining heads $(1-2)$ mounted on a base plate (3) facing a work slide (4) which is supported by an angle bracket (5) attached to the base plate. A three-jaw chuck (6) is mounted on the work slide and is used to clamp the button (7). The work slide is actuated by the air cylinder (8) and controlled by a four-way balanced-to-center manually operated valve. This provides a means for positioning the button in front of the far machining head for the spotfacing operation, in front of the near machining head for the core sample cutting, and at mid-position for loading, unloading, and sample extraction. Spotfacing rids the button surface of contamination and provides a flat circular sealing area for the chip catcher (9) to contact.

The work slide stop bar (10), with limit switches (11-12) attached, is mounted on the top of the work slide base (13). The fixed stops (14-15) are located to allow the slide to move the exact spindle-to-spindle center distance, thus assuring that the core sample tool will start cutting at 
BNWL - 7769

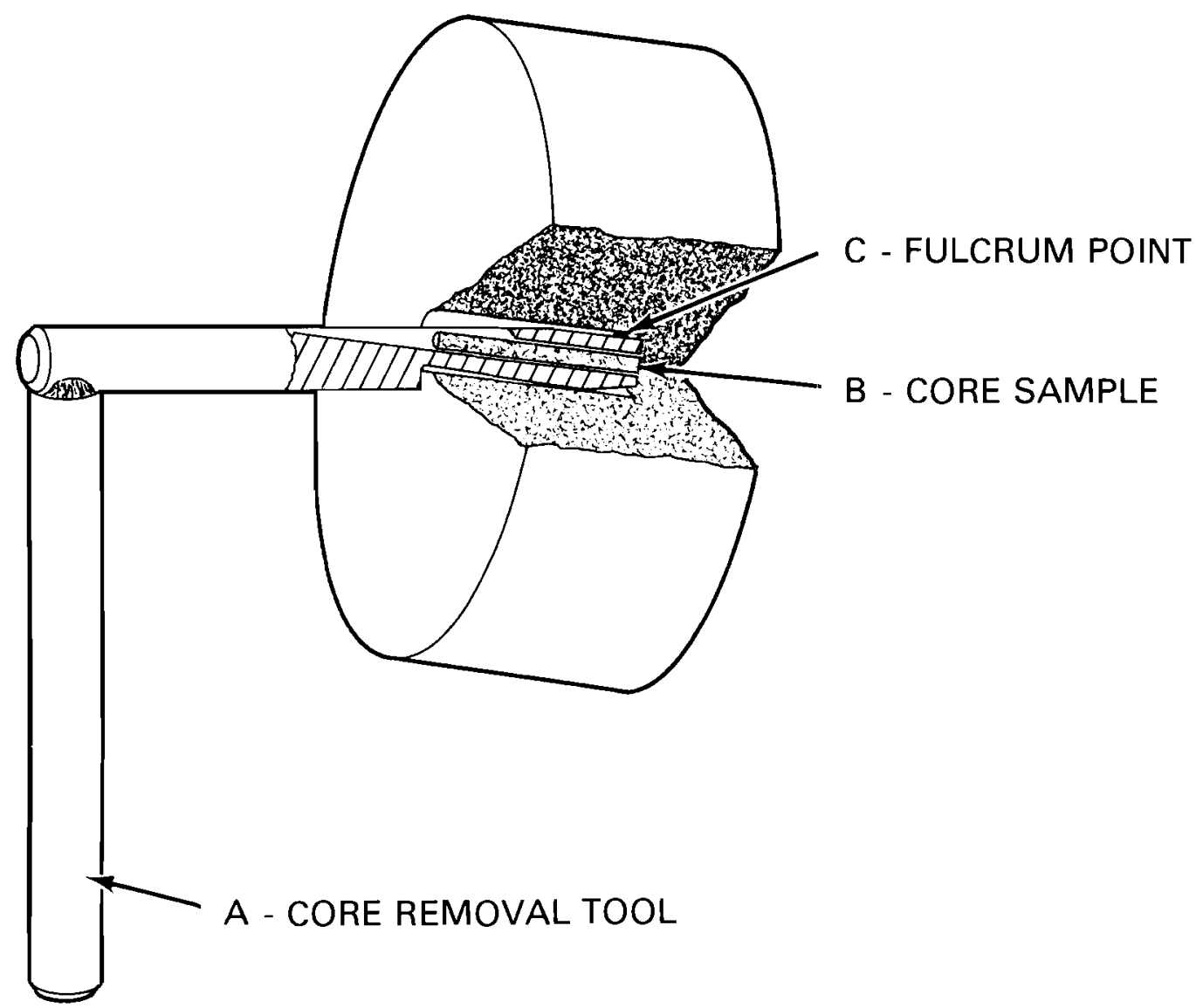

FIGURE 9. Core Removal Tool 
BNWL-1769

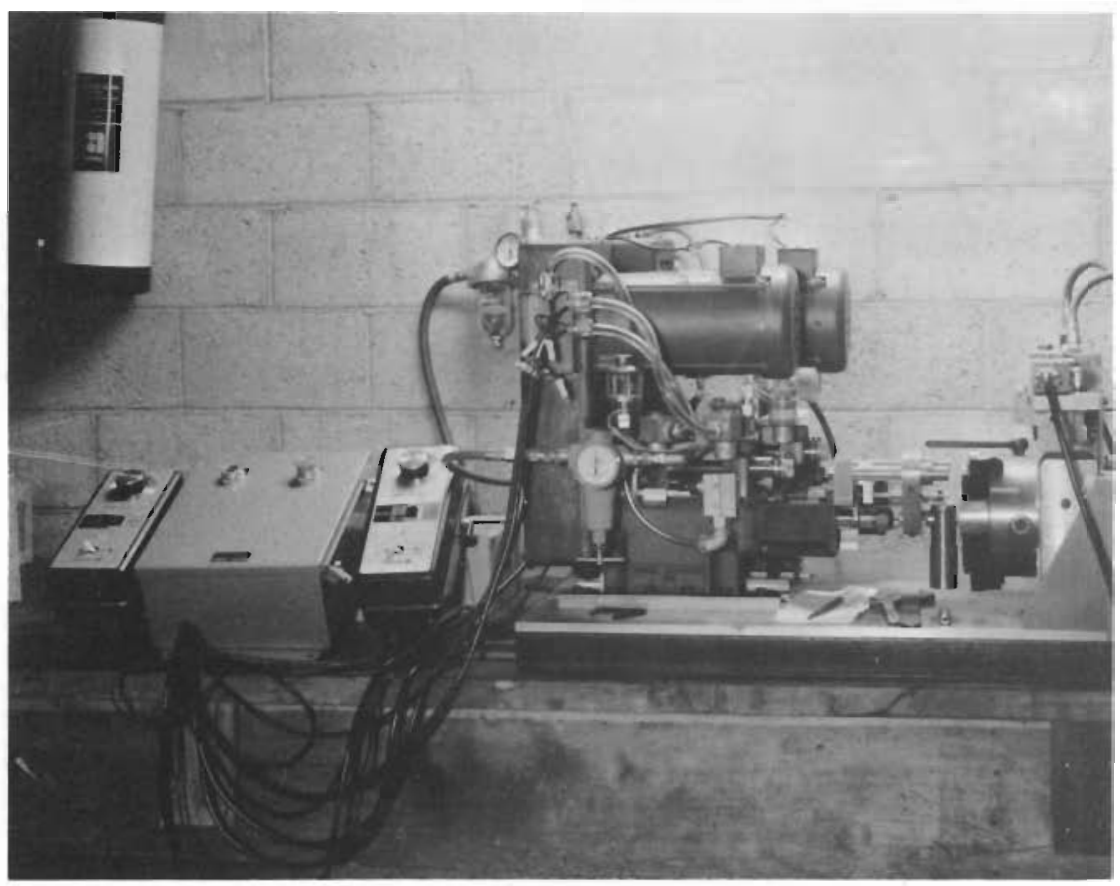

FIGURE 10. Core Sampling Machine and Controls

FIGURE 11. Close-Up of Core Sampling Apparatus

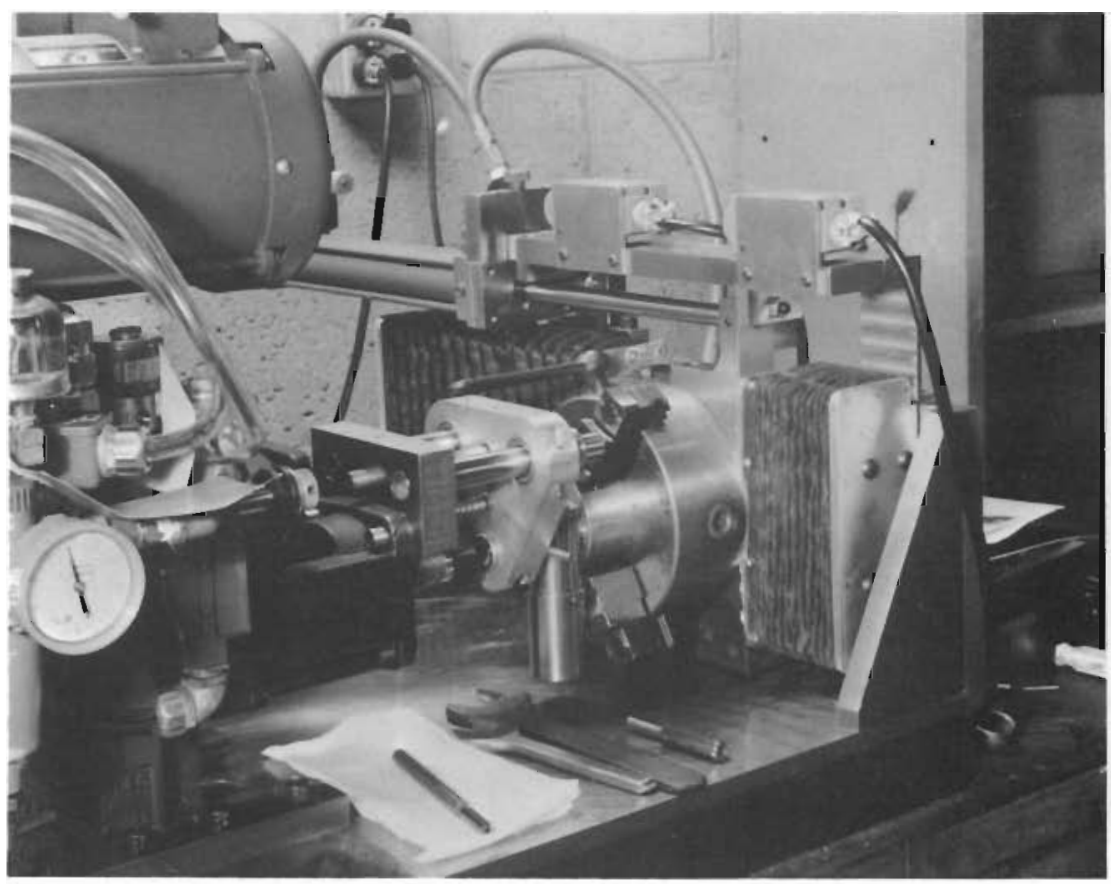


尔

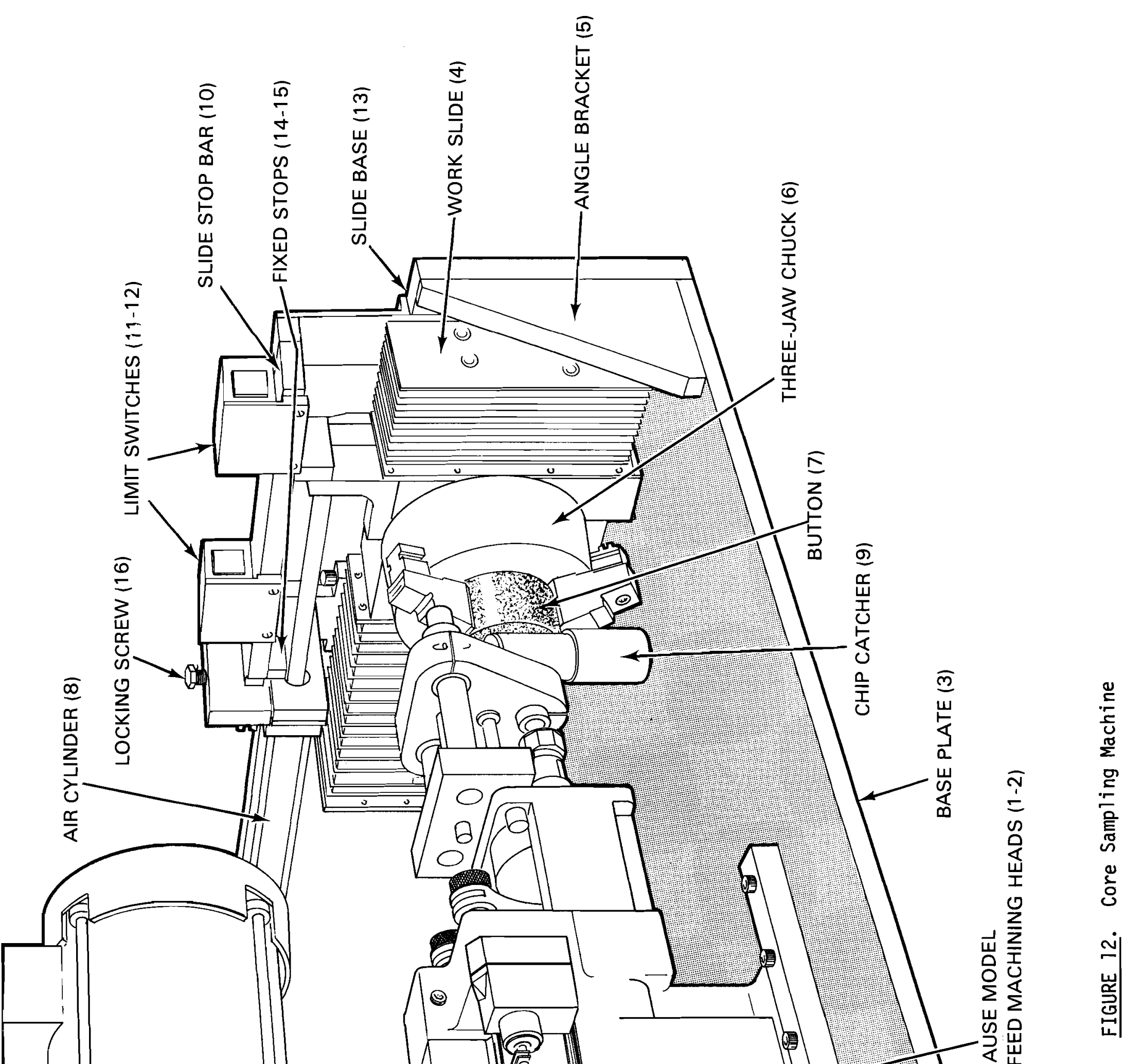


the center of the spotfaced area. In addition, the stop bar may be positioned at any point desired with the locking screw (16). The limit switches prevent either machining head from functioning until the work slide is precisely positioned in front of it.

\section{Chip Catching Mechanism}

A description of the chip catching mechanism and its functions follow; see Figure 8 . When the near machining head is in the normal off position, its spindle is fully retracted. With the spindle in this position, the return rod yoke (6) bears against a square shoulder machined on the collet holder, retracting the chip catcher (2) approximately $1 / 8 \mathrm{in}$. by means of the collar (14) to allow clearance for button positioning. Then the button, which has been previously spotfaced as a preparatory machining operation by the far machining head, is moved into position for core sampling in front of the near machining head. Next the cycle start button is depressed; this starts the drill spindle turning and feeding forward and simultaneously turns on the nitrogen purge gas as the solenoid valve is energized. As the drill moves forward, the sealing surface of the catcher (2) contacts the spotfaced area on the button preventing the chips from escaping. Shortly thereafter the core sample tool (16) starts cutting.

The core sample tool is supported by the two tungsten carbide bushings in the catcher; these bushings also act to induce the nitrogen gas through the core sample tool. The catcher is clamped rigidly in the guide plate (4) and is held against the alpha-plutonium button by the spring (12) which is guided by the return rod (6) and supported by the guide (8). While the 
drill is advancing, the guide plate (4) is rigidly supported by the ball bushing shafts (20) and the ball bushings (13) which are held securely in the support (3) which is bolted firmly to the machine frame. The shaft (9) is held tightly in the support (3) by means of a set screw (17).

Its purpose is to provide adjustment and support to the guide (8). As drilling progresses the chips are expelled from the hole into the catcher (2) and the container (5) by means of the nitrogen gas. The wire cloth (15), held in place by the clamp (7) and the screws (11), gives the gas an escape route and holds the chips back. A baffle is used in the catcher to prevent erosion of the wire cloth. RECOMMENDATIONS

The motor control start/stop switches should be replaced with relays to control the DC. These relays would be activated by the closing of LS-1 or LS-2 micro-switches, see circuit diagram, Figure 13. This would give assurance that the respective spindle would start turning as the feed was activated by closing the cycle start switch.

In addition, the motor controllers should be tied into the $A C$ circuit before any of the other components so the $A C$ portion will remain energized at all times. As it is the spindle motors are turned off by breaking the $A C$, this is improper and according to instructions accompanying the motor controller, may cause damage.

In the meantime to avoid damage, the controllers should be connected directly to $A C$ and operated manually until wiring corrections are made. Another circuit change is necessary to further improve the system. It would require replacement of the LS-1 and LS-2 micro-switches with 
double-pole double-throw components. Then each switch could be tied into the lock-in circuit to $1 \mathrm{CR}$. This would cause $1 \mathrm{CR}$ to drop out, automatically retracting the spindle as soon as the slide was moved away from either the LS-1 or LS-2 micro-switches. As it is now 1 CR does not drop out and the units can continue to feed without the spindle turning.

Some of the chips produced in cutting the core sample are held against the wire cloth in the chip catcher by the escaping nitrogen gas. They tend to cling and remain there after the sampling operation is completed and the gas is turned off. A means of flushing these chips down into the container could be provided by adding a length of tubing to direct the nitrogen gas downward through the wire cloth. It should be attached to the front of the guide plate by means of a screw held clip, using the tapped hole provided. A foot switch and a solenoid valve from the nitrogen source to the tube would provide a simple way of applying the gas. This would be needed only if chips are to be used as analytical samples. 


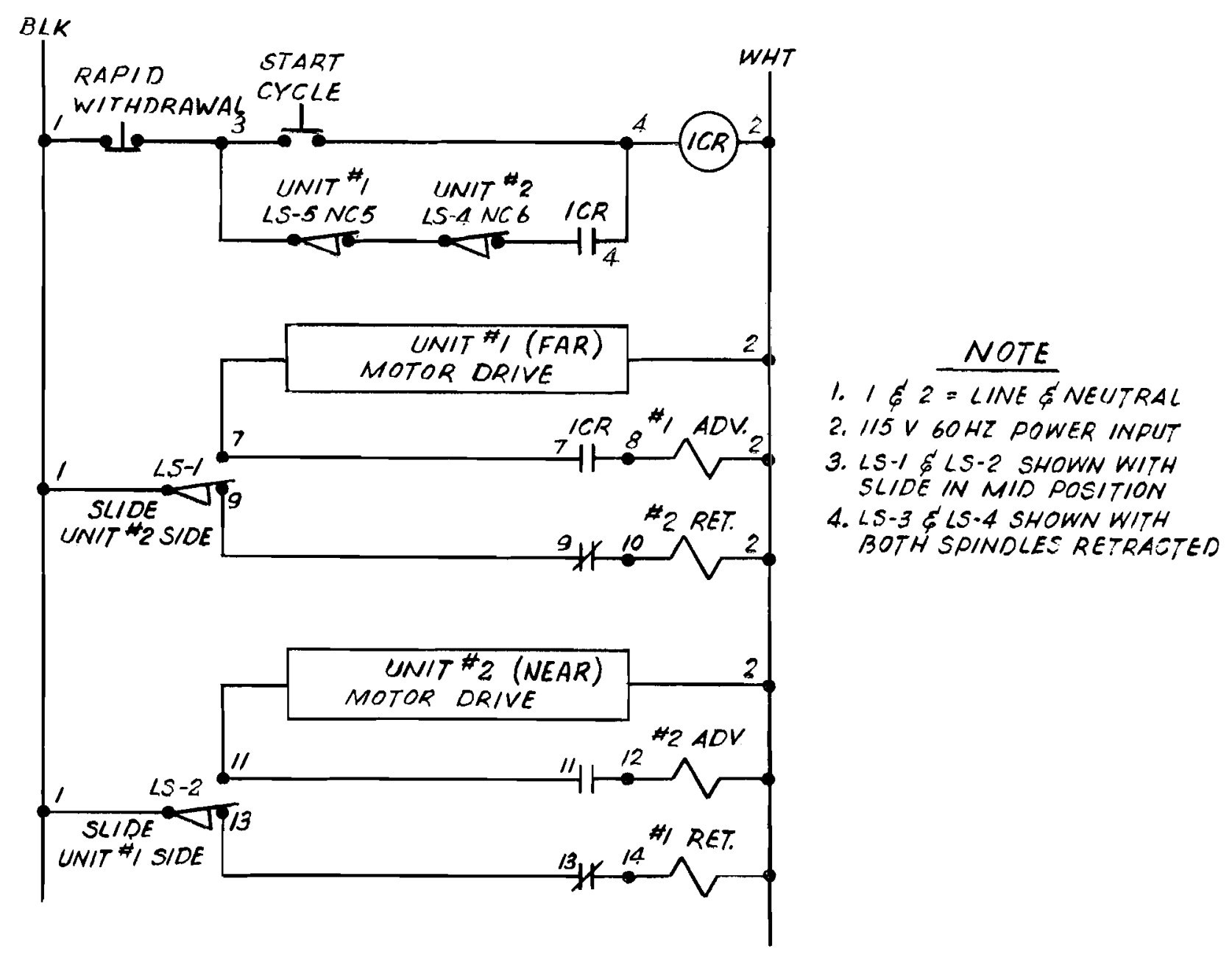

FIGURE 13. Circuit Diagram of the Electrical Control System 


\section{DISTRIBUT ION}

No. of

Copies

OFFSITE

1

AEC-HQ Division of Military Application

Col. H. W. Parlett

1

AEC-Chicago Patent Attorney

G. H. Lee

3

AEC Technical Information Center

UC-Special

9

DOW-Rocky Flats

H. E. Bowman

R. D. Forest

F. J. Fraikor

W. H. Hauschildt

A. R. Konecny

L. W. Pribila

J. R. Seed

D. K. Thistlewood

J. F. Willging

3

DuPont/Savannah River

Technical Library

$1 \quad$ LASL-LoS A1amos

W. J. Maraman

6

LLL-Livermore
G. A. Broadman
C. R. Henry
A. J. Hodges
J. 0. Jepson
K. R. Ker
J. L. Robbins 
Copies

ONSITE - HANFORD

1 AEC/RL Patent Attorney

R. M. Poteat

2

AEC Richland Operations Office

0. J. Elgert

B. J. Melton

AEC/RL-RDT Senior Site Representative, PNP

$F$. Standerfer

13 Atlantic Richfield Hanford Company

H. H. Curtis

R. E. Felt

R. D. Fox

J. V. Gilchrist

A. H. Hinkson

L. M. Knights

G. A. Nicholson (3)

R. A. Pease (3)

A. E. Smith

Battelle-Northwest

V. C. Asmund

H. L. Butts

D. L. Condotta

J. C. Dunn

R. E. Falkoski

H. R. Gardner

H. L. Henry

R. R. King

L. Lahart

iv. Laegreid

E. D. McClanahan

D. M. Miller (12)

R. W. Moss

R. D. Nelson

J. W. Patten

R. W. Stewart

R. D. Tillson

W. B. Weihermiller

0. J. Wick

Technical Information (5) 